The Ordinal Efficiency of Betting Markets: an exploded logit approach

\begin{tabular}{|c|c|}
\hline Journal: & Applied Economics \\
\hline Manuscript ID: & APE-08-0263.R1 \\
\hline Journal Selection: & Applied Economics \\
\hline $\begin{array}{r}\text { Date Submitted by the } \\
\text { Author: }\end{array}$ & 25-Jun-2008 \\
\hline Complete List of Authors: & $\begin{array}{l}\text { Johnson, Johnnie; University of Southampton, Centre for Risk } \\
\text { Research } \\
\text { bruce, alistair; University of nottingham, business school } \\
\text { Yu, Jiejun; University of Nottingham, Business School }\end{array}$ \\
\hline JEL Code: & $\begin{array}{l}\text { D82 - Asymmetric and Private Information < D8 - Information and } \\
\text { Uncertainty < D - Microeconomics, G14 - Information and Market } \\
\text { Efficiency|Event Studies < G1 - General Financial Markets < G - } \\
\text { Financial Economics, E37 - Forecasting and Simulation < E3 - } \\
\text { Prices, Business Fluctuations, and Cycles < E - Macroeconomics and } \\
\text { Monetary Economics, L83 - Sports |Gambling|Recreation|Tourism < } \\
\text { L8 - Industry Studies: Services < L - Industrial Organization, D84 - } \\
\text { Expectations|Speculations < D8 - Information and Uncertainty < D } \\
\text { - Microeconomics }\end{array}$ \\
\hline Keywords: & market efficiency, betting, information \\
\hline
\end{tabular}




\title{
The Ordinal Efficiency of Betting Markets: an Exploded Logit Approach
}

Johnnie Johnson, Centre for Risk Research, University of Southampton, Highfield, Southampton, UK

Alistair Bruce, Nottingham University Business School, Jubilee Campus, Nottingham, UK

Jane Yu, Nottingham University Business School, Jubilee Campus, Nottingham, UK

Running Title: Ordinal Efficiency of Betting Markets

\begin{abstract}
This paper offers a new perspective on efficiency in betting markets by examining the degree to which finishing order in horseraces corresponds to probabilities inherent in odds across different categories of horserace. The application of an exploded logit procedure reveals a significantly greater degree of ordinal efficiency in higher relative to lower class races. Explanations for the phenomenon include differences in prize-related incentives, cross-market distinctions in information markets and differential opportunity/incentive for market manipulation.
\end{abstract}

Corresponding Author:

Alistair Bruce, Nottingham University Business School, Jubilee Campus, Nottingham, UK

e-mail: alistair.bruce@nottingham.ac.uk 


\section{The Ordinal Efficiency of Betting Markets: An Exploded Logit Approach}

\section{Introduction}

This paper offers a new perspective on the issue of the efficiency of horserace betting markets by the application of an exploded logit procedure to test the reliability of prices (odds) in predicting the order of finish of horses in races. The emphasis on ordinal efficiency which this technique permits offers a new and distinctive insight into the wider efficiency question and reveals important distinctions between markets associated with different classes of race.

From a betting perspective, enriching understanding of ordinal efficiency is important given that bet types which seek to predict the first and second or the first, second and third finishers in a race (e.g. 'forecast' and 'tricast' bets) are an established and popular feature of both bookmaker and pari-mutuel betting markets in the UK and elsewhere. Important aspects of the regulatory framework within which British horseracing takes place underscore the significance of the concept of ordinal efficiency. The rules of racing, as 
administered in the UK by the Horseracing Regulatory Authority, explicitly require any horse participating in a race to be ridden so as to gain its best possible finishing position. Horses, trainers and jockeys investigated under the so-called 'non-trier's rule' (prior to March 2000, Rule 151; now Rules 155-157, British Horseracing Board/Horseracing Regulatory Authority (2006)) may suffer penalties where they have been found to infringe its terms. In theory these regulatory arrangements should offer some reassurance to bettors. They imply that, ceteris paribus, if the regulatory regime operates effectively and if the odds on individual horses reflect accurately their relative chances of success, then the finishing order of horses might be expected to mirror the ascending profile of odds. This said, it is of course the case that the regulatory environment and the sanctions which form part of it, is just one of many potential factors influencing behaviour, performance and ultimately the outcome of a horserace. The particular advantage of the concept of ordinal efficiency introduced in this paper is therefore its explicit focus on the ability of the market to predict the order of finish, and not just the winner, in horseraces.

The paper proceeds as follows. Section II offers a brief discussion of the existing betting market efficiency literature in order to set the context for this contribution. This is followed in 
Section III by an introduction to the exploded logit technique. Section IV outlines data and methods employed. Section V presents results, which are interpreted in Section VI, and concluding remarks follow.

\section{Betting Market Efficiency}

No topic has received more attention in the academic literature relating to betting markets than that of market efficiency. For half a century, the research agenda in this area has been dominated by investigations regarding the degree to which prices in betting markets reliably embody and reflect information relevant to the market outcome. This has involved consideration of various forms of efficiency (' weak', 'semistrong' and 'strong') which address the incorporation into prices of different forms or layers of more and less transparent information (for an extensive and recent survey of these areas, see Vaughan Williams (2005)). The literature has also embraced the study of betting markets in widely differing international contexts and the study of distinct forms of betting market (e.g. pari-mutuel, see for example, Hoerl and Fallin (1974), Asch, Malkiel and Quandt (1982); bookmaker, see, for example, 
Dowie (1976)). Within the study of particular market forms, a range of approaches to the exploration of pockets of market inefficiency has been employed, including segmentation of market activity by bet type, by timing of bet (Kopelman and Minkin (1991), Johnson and Bruce (1993)), or by type of bettor (e.g. motivation, utility function; see, for example, Snyder (1978), Thaler and Ziemba (1988), Bruce and Johnson (1992) Busche (1994)).

Momentum in relation to the study of efficiency issues has been sustained in recent years by a number of factors. These include the development of traditional betting markets into new territories in terms of betting events, new forms of bet and betting market e.g. betting exchanges, spread betting and significant reconfiguration of regulatory arrangements in relation to betting. Each of these has prompted new and wider research into efficiency characteristics across a broad range of geographical and sporting contexts (see, for example, Gander et al (2001) (New Zealand horseracing); Sobel and Raines (2003) (American greyhound racing); Dare and Holland (2004), Boulier et al (2006) (American football), Winter and Kukuk (2008) (German horseracing) and for a collection of articles which reflects the diversity of themes relating to contemporary betting 
and wagering issues, including efficiency studies, see the Special Issue of this Journal, (2008, Volume 40:1)). Whilst the volume and range of work in the area of betting market efficiency is clearly extensive, therefore, there is a reasonable consensus around two themes. First, there are established biases in betting markets in terms of patterns of misalignment between subjective and objective probabilities which appear generally (though not universally) robust to different market and national contexts. Second, despite the existence of these biases, the opportunities for developing operationally viable and profitable betting strategies appear highly limited.

As noted above, the dominant basis for evaluating efficiency in horserace betting markets has, in simple terms, relied on comparing the probabilities of success implied by particular sets of odds with the actual probability of success of horses with those odds, as revealed by race outcomes. This allows an insight into the reliability of odds in predicting winning outcomes, but it says nothing directly about the reliability of odds in predicting the order in which horses finish within a particular race or set of races. As such, it neglects a dimension of market efficiency, the ability of market prices to rank effectively the probability of outcomes within a market. This is 
where the application of an exploded logit procedure has the potential to enrich our understanding. The significance of this for rank-based bet types and in relation to the regulatory framework of horseracing was noted above. It is also worth noting here that the odds of a horse in a UK bookmaker market, whilst directly reflecting the market's view of its chance of winning and determining the return to a winning bet, also affect returns to bets invested on a horse to finish in second, third or fourth place. Depending on the race conditions, odds applied to a 'placed' horse derive directly from the odds in the 'win' market. For example, in a handicap race of 14 runners, the return to a placed horse (positions 2 and 3 ) is one quarter of its 'to win' odds, whereas for a non-handicap race with eight runners, the returns to a placed horse (positions 2 and 3) are calculated as one fifth of its 'to win' odds. These formulae are part of the set of rules which are overseen by the Horseracing Regulatory Authority, the governing body of UK racing, and which apply to all licensed bookmakers operating in the UK. It is clear from the above that, in bookmaker markets, an implicit assumption is that the probability of a horse being placed is a function of the probability that the horse will win the race. This adds further significance to the testing for ordinal efficiency investigated here. In particular, the application of the exploded logit model challenges the simplistic assumption 
implicit in the Harville (1973) approach, whereby the relationship between a horse's finishing position and its performance relative to other horses is seen as a given, irrespective of that finishing position.

\section{The Exploded Logit Technique}

In general terms, the exploded logit technique offers a basis for analysing ranked data by decomposing a single observation of J ranked alternatives into J-1 'pseudo-observations' of rankings. This involves, initially, discarding the first-ranked alternative from the original observation and then repeating this process, discarding the subsequently first-ranked alternatives to leave successively smaller sets of ranked alternatives. Essentially, as Chapman and Staelin (1982) note, this explosion process, based on Luce and Suppes's (1965) Ranking Choice Theorem, exploits additional information inherent in the rank ordered choice sets. Bolton and Chapman (1986) point to the benefits in terms of more precise parameter estimates resulting from an increase in the number of independent choice sets available for analysis. In the context of horserace betting data, taking the finishing order of $\mathrm{J}$ horses in a race as the initial observation, we remove the winner to produce a second 'pseudo-observation' where the second placed horse is the 'winner'; in a similar way, removal 
of the second placed horse produces a further observation, where the third placed horse is the 'winner'.

The exploded logit procedure enables testing of the reliability of the odds in correctly ranking the order of finishers in a horserace as successive elimination of winners reaches further down the ranking and the original observation 'explodes' into multiple observations. The greater the 'depth' of explosion possible, that is to say the degree to which successive subsets of data can be viably pooled as independent events, the more reliable is the ranking. The focus of interest in this study is on the efficiency of the market in predicting the order of finish of the first three horses in a race. This reflects the fact that, in the UK market, bet types which relate to the order of finishing are confined to prediction of first and second or first, second and third places, as noted above.

In framing the empirical enquiry, we draw on previous research relating to the efficiency characteristics of horserace betting markets which has investigated efficiency distinctions between different classes of race (Vaughan Williams and Paton (1997)). The class of a horserace, as identified by its official designation under the auspices of the British Horseracing Board (now part of the Horseracing Regulatory Authority), reflects the fact that different races are designed to attract horses of differing levels 
of ability, so that the aggregate population of racehorses is provided with regular opportunities to compete. As well as being highly correlated with the ability of participating horses, race classes are characterised by an extended hierarchy of prize money. When the races under scrutiny in this study took place, the class system designated races on a scale of $A$ (highest) to $H$ (lowest), with each category populated by both handicap and non-handicap races.

A feature of class-based discrimination between sets of races has been an identifiably greater susceptibility of low class races to a well-established aspect of inefficiency, favourite-longshot bias (the propensity to overbet on long odds horses and underbet on short odds horses), compared with high class races (Bruce and Johnson (2005)). The explanation for these differing degrees of efficiency relates principally to the differences in the information environments between the high and low grade categories. Specifically, the higher class races (and associated betting markets) attract wide media interest and analysis where, prima facie, the opportunity to conceal, and benefit from, privileged information would appear to be limited. The latter category represents the opposite extreme, featuring low class events with little or no attendant media coverage. The contention, put simply, is that in betting markets associated with this latter category, the opportunity to conceal and profit 
from privileged information is greater. A full exposition of this argument is provided in Bruce and Johnson (2005). Accordingly, drawing on this earlier class-based literature, the central proposition to be examined in this paper is whether, in terms of ordinal efficiency, the relative efficiency characteristics of, respectively, high grade and low grade races mimic the relative efficiencies in terms of the alignment of subjective (odds-based) and objective (revealed) probabilities. More specifically, are markets in higher grade races more ordinally efficient than their lower grade race equivalents? In pursuing this issue, the categories employed to probe cross-category distinctions in Bruce and Johnson (2005), is replicated here; the set of races is split between two separate categories; race classes A-C and race classes D-H (non-handicap only), this reflecting the system of race classification in operation when the races under scrutiny took place. The exclusion of handicap races in categories $\mathrm{D}-\mathrm{H}$ requires explanation. The basis for focusing on non-handicap lower grade races is that the terms of handicap races, at any level, are determined by the decisions of the independent handicapper, whose role is to assign weights to horses to induce a competitive contest. In non-handicap races, however, this independent moderating influence is absent and the terms on which non-handicap races are run may be partly determined by horses' 'connections' (owner, trainer). For 
example, in certain lower class events such as claiming races, horses' weights may be influenced by the value which connections place on the horse (in terms of the price for which the horse may be bought after the race). This element of discretion vested in connections, may create an incentive to influence race terms in order to profit from subsequent betting activity. It should be noted, in emphasising this point, that the financial rewards (in terms of prize money) in non-handicap low grade races are lower than in any other race type, so that the potential betting returns/prize money ratio in such events is significantly greater than for higher grade races.

\section{Data and Method}

The data employed are drawn from a dataset of races run at 893 race meetings, held between August $29^{\text {th }} 1997$ and $31^{\text {st }}$ July 1998 inclusive at UK racecourses. Races with fewer than three runners were excluded from the sample, as were races where horses tied for first, second or third place and races where a horse or horses were withdrawn. This gave a total of 2184 races and 26060 runners, 588 races (7030 runners) in Class A-C and 1596 races (19030 runners) in Class D-H (non-handicap). Race outcomes, including the order of finishers in each race, are 
available from a range of sources. For the purposes of this study the statistical records published in the specialist horseracing media were employed.

The basis of the exploded logit technique is the development of a conditional logit model to estimate the 'winningness' of a horse. The 'winningness index' is defined as follows:

$w_{i j}=\theta \ln \left(p_{i, j}^{\text {odds }}\right)+\xi_{i j}$

where $p_{i, j}^{\text {odds }}=\frac{q_{i j}}{\sum_{i=1}^{h} q_{i j}}$

and where $\quad q_{i j}=\frac{1}{o_{i j}+1}$,

$\theta$ is the parameter to be estimated, $\xi_{i j}$ is the error term. $p_{i, j}^{\text {odd }}$ is the probability of winning (implied by the starting price) of horse $i$ in race $j ; h$ is the total number of horses in race $j$ and $o_{i j}$ is the starting price of horse $\mathrm{i}$ in race $\mathrm{j}$.

Consequently, we can predict the probability of horse i winning race $\mathrm{j}\left(p_{i, j}\right)$ as follows:

$$
p_{i, j}=\frac{\exp \left(\theta \ln \left(p_{i, j}^{\text {odds }}\right)\right)}{\sum_{i=1}^{n_{j}} \exp \left(\theta \ln \left(p_{i, j}^{\text {odds }}\right)\right)}
$$


The parameter $\theta$ is estimated by maximizing the joint probability of observing the results of all $\mathrm{J}$ races in the sample.

Formally, we define $E$ as the depth of explosion, and $J(E)$ refers to the number of independent choice set observations that could be generated from $\mathrm{j}$ races. There are two tests which address the issue of the appropriate depth of explosion.

The first, a chi-squared statistic based on Watson and Westin (1975) involves grouping observations by depth of explosion and sequentially testing the viability of pooling observations of successive explosion depths.

To test if a move from $E=1$ to $E=2$ is appropriate, we test the null hypothesis as:

$$
\begin{aligned}
& H_{0}: \theta^{(1)}=\theta^{(2)} \\
& \chi^{2}=-2\left\{L\left(\theta=\hat{\theta}^{(1+2)}\right)-\left[L\left(\theta=\hat{\theta}^{(1)}\right)+L\left(\theta=\hat{\theta}^{(2)}\right)\right]\right\}
\end{aligned}
$$

where $\hat{\theta}^{(1+2)}$ is the Maximum Likelihood Estimate (MLE) obtained by pooling the two data subsets; $\hat{\theta}^{(1)}$ and $\hat{\theta}^{(2)}$ are the MLEs for the two data subsets respectively and 
$L\left(\theta=\hat{\theta}^{(1+2)}\right), L\left(\theta=\hat{\theta}^{(1)}\right), L\left(\theta=\hat{\theta}^{(2)}\right)$ are the log-likelihood functions for corresponding estimations. This test statistic will be asymptotically distributed $\chi^{2}$ with $\mathrm{N}$ degrees of freedom. The degree of freedom in our tests is 1 , corresponding to the number of variables in the conditional logit model. (Wald 1943).

Similarly, to test if a move from $E=2$ to $E=3$ is appropriate, we test:

$$
\begin{aligned}
& H_{0}: \theta^{(2)}=\theta^{(3)} \\
& \chi^{2}=-2\left\{L\left(\theta=\hat{\theta}^{(1+2+3)}\right)-\left[L\left(\theta=\hat{\theta}^{(1+2)}\right)+L\left(\theta=\hat{\theta}^{(3)}\right)\right]\right\}
\end{aligned}
$$

The second test involves calculating the value of the likelihood ratio index for successive depths of explosion such as:

$$
R^{2}=1-\frac{L(\theta=\hat{\theta})}{L(\theta=0)} \sim(0,1)
$$

where $L(\theta=\hat{\theta})$ is the value of the log-likelihood function at the estimated parameters and $L(\theta=0)$ is its value when all the parameters are set equal to zero.

Here, given that the index is not dependant on the number of observations, calculated $\mathrm{R}$ squared values should remain approximately constant as depth of explosion increases unless a 
round of explosion introduces 'noisy' observations, in which case R squared values would decline significantly, signalling the inappropriateness of that round.

\section{Results}

The results indicate that there is a significant distinction between high and low-grade races in terms of the depth of viability of explosion. Table 1 reports the log likelihood ratio and the chi-squared statistic.

[Table 1 about here]

For race classes $\mathrm{A}-\mathrm{C}$, the $\chi^{2}$ statistic is 1.954 for an explosion depth of two $(E=2)$, and 2.994 for an explosion depth of three. $(E=3)$. Neither value is rejected by the null hypothesis, given the critical value of $\chi^{2}(1)$ is 6.635 at the $1 \%$ level of statistical significance. It suggests the reliability of exploding the data to a depth of 3 .

For race class D-H (non-handicap only), the $\chi^{2}$ statistics is 23.864 for $E=2$ and 42.9174 for $E=3$. Both are rejected by the null-hypothesis.

Table 2 presents the R-Squared results for race classes $A-C$ and race classes $\mathrm{D}-\mathrm{H}$ (non-handicap only). 
[Table 2 about here]

The results demonstrate that, for race classes $A-C$, with the increasing depth of explosion, R-squared is increasing slightly. (i.e., for classes A-C, R-Squared for $E=1$ is 0.40674 and it increases to 0.41115 for $E=2$ and 0.41984 for $E=3$ ); On the contrary, for race classes $\mathrm{D}-\mathrm{H}$ (non-handicap only), the Rsquared is gradually decreasing. For $E=1, E=2, E=3$ respectively, $\mathrm{R}$-squared is $0.45026,0.42989$ and 0.42063 .

The results from both tests indicate clearly that the viability of explosion for high class races exceeds that of low grade, nonhandicap races, across those finishing places relevant to rankbased betting activity.

\section{Interpretation}

The effects revealed via the application of the exploded logit technique to different class-based race groups echo efficiency distinctions reported in earlier work (Bruce and Johnson (2005)). Specifically, there is evidence that, in terms of ordinal efficiency, the higher grade race category outperforms the lower class group over the critical range, in terms of rank-based betting options, of horses placed first, second and third.. Explanations advanced in relation to the earlier results centred 
on the relative informational characteristics of the race groups and in particular the differential opportunities to profit from privately-held information across the two groups. In particular, the transparency of the betting environment for high class races was regarded as likely to inhibit strategies based on the retention and exploitation of privileged and valuable information, whereas profitable exploitation of such information advantages was regarded as viable in markets relating to lower grade events. The nature of the efficiency measure employed here is, of course, different. As such, the interpretation is required specifically to explain why the market odds constitute a more powerful basis for predicting ranking of horses in a race for high class vis-à-vis low class races.

One element of explanation may relate to differential incentives to secure the highest possible finishing place for a horse as between high and low class races. Invariably, the class of a race and the prize money associated with winning or being placed in a race are highly correlated. The highest grade races in the UK feature levels of winning prize money which differ from the lowest grade prize equivalent by a factor of approximately 200 . Prizes for placed horses (sometimes extending to awards for sixth place) in major events can significantly exceed winning prize money for low grade races. As such, the incentive to 
pursue the possibility of a place prize in a high class event is significantly more potent than that in a low class race. This in itself would suggest that placed positions in high class races are more vigorously competed for than in low class races. Indeed, in explaining differential bias across race classes, Bruce and Johnson (2005) point to the relative financial benefits from betting vis-à-vis prize money in low class events.

If the financial (prize money) incentives associated with achieving the best possible finishing place are more potent in high class races, then it could also be argued that the sanctions for not maximising finishing position are also less severe in low class races. This reflects the fact that media and public scrutiny of low class events is much less intense than for high class equivalents; the probability of 'non-trying' behaviour being identified and acted upon by the horseracing authorities is consequently smaller.

Rather more mundanely, it might be argued that the informationally impoverished betting environment in low class races might be expected to generate a more random pattern of betting activity compared with high class, information rich races, a factor which might help to explain the weaker ranking performance of prices in lower class events. 
One way in which lower class races may offer holders of privileged information (insiders) greater opportunities to benefit from its exploitation than high class events is via market manipulation in lower grade races. In markets with relatively low betting volumes, in particular, which tend to be a characteristic of lower class races, there may exist an incentive to induce particular patterns of betting in the wider population which are ultimately to the advantage of the manipulator. Bruce, Johnson and Tang (2005) identify two types of strategy in this context, depending on the 'insider' view of the demographic composition of the betting market. With each strategy, the point is that insiders send signals into the market, via their investment behaviour, which are unrelated to their real perceptions of likely outcome, with a view to triggering responses from the general population of bettors. These responses contribute to more advantageous rates of return to insiders, but because they are essentially 'false signals' they introduce informational inefficiencies into the set of price data, or odds. These are evidenced in terms of a distribution of odds in lower grade races which more closely approximates to a random pattern of betting activity. 


\section{Conclusion}

This paper has exploited the exploded logit technique to develop a richer understanding of the efficiency characteristics of betting markets. This technique permits analysis of the degree to which the order of finishers in a horserace reflects the order inherent in the odds of horses in the associated betting market ( 'ordinal efficiency'). This perspective adds to more established views of market efficiency which rely more on comparing the objective (i.e. realised) probabilities of success for horses across different odds/odds ranges with the subjective probabilities embedded in the odds.

The results point to significant differences in across established groups of races defined in terms of the standard industry classification, with higher class races displaying marked superiority in ordinal efficiency. Possible explanations for this effect are considered, including differences in prize-related incentives, informational environments and opportunities for market manipulation.

In terms of the implications of this study for those directly involved in the racing and betting industries, the superior ordinal efficiency in the higher class race category would 
suggest that those who engage in rank-based betting in such races may benefit from the signals embodied in price information, whereas such signals appear unreliable in lower class events. From the regulatory perspective, there may be grounds for considering increased scrutiny of lower grade races, where the results offer at least prima facie grounds for suggesting that the incentive to comply with the rules of racing may be less sharp than it is in higher grade events. 


\section{Table 1: Log Likelihood Values and $\chi^{2}$ Statistics by Observation Group and Race Category}

This table reports the log likelihood value for each observation group. $\chi^{2}$ statistics are calculated to examine whether the choice set data can be pooled to level E. Critical values of $\chi^{2}(1)$ are 6.635 and 3.841 at the $1 \%$ and $5 \%$ level of statistical significance.

\section{Class ABC}

\section{Choice}

Observation

No. of

\begin{tabular}{cccc} 
Group & races & & $\chi^{2}$ \\
\hline$J(E=1)$ & 588 & $L\left(\theta=\hat{\theta}^{(1)}\right)=-1259.625$ & \\
$J(E=2)-J(E=1)$ & 588 & $L\left(\theta=\hat{\theta}^{(2)}\right)=-1239.913$ & \\
$J(E=3)-J(E=2)$ & 588 & $L\left(\theta=\hat{\theta}^{(3)}\right)=-1193.408$ & \\
$J(E=2)$ & 1176 & $L\left(\theta=\hat{\theta}^{(1+2)}\right)=-2500.515$ & $\mathbf{1 . 9 5 4}$ \\
$J(E=3)$ & 1764 & $L\left(\theta=\hat{\theta}^{(1+2+3)}\right)=-3695.420$ & $\mathbf{2 . 9 9 4}$ \\
\hline
\end{tabular}

\section{Class D-H (non-handicap only)}

\begin{tabular}{|c|c|c|c|}
\hline $\begin{array}{c}\text { Choice } \\
\text { Observation } \\
\text { Group }\end{array}$ & $\begin{array}{l}\text { No. of } \\
\text { races }\end{array}$ & Log Likelihood & $\chi^{2}$ \\
\hline$J(E=1)$ & 1596 & $L\left(\theta=\hat{\theta}^{(1)}\right)=-2858.609$ & \\
\hline$J(E=2)-J(E=1)$ & 1596 & $L\left(\theta=\hat{\theta}^{(2)}\right)=-3058.485$ & \\
\hline$J(E=3)-J(E=2)$ & 1596 & $L\left(\theta=\hat{\theta}^{(3)}\right)=-3087.478$ & \\
\hline$J(E=2)$ & 3192 & $L\left(\theta=\hat{\theta}^{(1+2)}\right)=-5929.026$ & 23.864 \\
\hline$J(E=3)$ & 4788 & $L\left(\theta=\hat{\theta}^{(1+2+3)}\right)=-9037.9627$ & 42.9174 \\
\hline
\end{tabular}


Table 2. Conditional Logit Model Results--Estimated with Explosion Depths of 1,2 and 3 for each Race Category

This table reports the estimated results using conditional logit models with explosion depths of 1,2 and 3 for the two race categories (A-C and D-H).

\section{Class ABC}

The Depth of

Explosion $E=1$

$\mathrm{E}=2$

$\mathrm{E}=3$

$\theta$

Standard

$\begin{array}{cccc}\theta & \text { Error } & \text { T-ratio } & \text { R-Squared } \\ 1.167277 & 7.06 \mathrm{E}-02 & 16.536 & 0.40674 \\ 1.098443 & 4.97 \mathrm{E}-02 & 22.093 & 0.41115 \\ 1.049485 & 4.05 \mathrm{E}-02 & 25.926 & 0.41984\end{array}$

\section{Class D-H (non-handicap only)}

The Depth

of

Explosion

$E=1$

$E=2$

$E=3$ $\theta$

1.28337

1.17194

1.08882
Standard

Error

3.31E-02

2.26E-02

1.82E-02
T-ratio

38.821

51.641

59.658
R-Squared

0.45026

0.42989

0.42063 


\section{References}

Asch P., B.G. Malkiel and R.E. Quandt (1982) 'Racetrack betting and informed Behaviour', Journal of Financial Economics, 10, 187-194.

Bolton, R. and R. G. Chapman. (1986) 'Searching for positive returns at the track: a multinomial logit model for handicapping horse races', Management Science, 32(8), 1040-1060.

Boulier, Brian L., H.O. Stekler and sarah Amundson (2006) 'Testing the efficiency of the National Football League betting market', Applied Economics, 38, 279-284.

British Horseracing Board / Horseracing Regulatory Authority (2006) 'The Orders and Rules of Racing', London.

Bruce A.C. and J.E.V. Johnson (1992) 'Toward an explanation of betting as a leisure pursuit', Leisure Studies, 11, 201-218.

Bruce, Alistair C., and Johnnie, E.V., Johnson, 2005, 'Market Ecology and Decision behaviour in state-contingent claims markets', Journal of Economic Behavior \& Organization, 56 (2), 199-217.

Bruce, Alistair C., Johnnie E.V. Johnson and Leilei Tang (2005) 'Trading Volume and Betting Market Efficiency: The Role of Insiders', paper presented at the European Association for the Study of Gambling Conference., Malmo, Sweden.

Busche, K. (1994) 'Efficient market results in an Asian Setting', in Donald B. Hausch, Victor S.Y.Lo and William T. Ziemba (eds.) Efficiency of Racetrack Betting Markets, London: Academic Press.

Chapman, R.G. and Staelin, R. (1982) 'Exploiting Rank Ordered Choice Set Data within the Stochastic utility Model', Journal of Marketing Research, 19, 288-301.

Dare, William H. and Steven Holland (2004) 'Efficiency in the NFL betting market: modifying and consolidating research methods', Applied Economics, 36, 9-15.

Dowie, J. (1976) 'On the Efficiency and Equity of Betting Markets', Economica, 43, 139-150. 
Gander, J.M., Richard A. Zuber and R. Stafford Johnson (2001) 'Searching for the favourite-longshot bias down under: an examination of the New Zealand pari-mutuel betting market', Applied Economics, 33, 1621-1629.

Harville, D.A. (1973) 'Assigning Probabilities to the outcome of Multi-Entry Competitions', Journal of the American Statistical Association, 68, 312-316.

Hoerl, A.E. and Fallin, H.K. (1974) 'Reliability of Subjective Evaluations in a High Incentive Situation' Journal of the Royal Statistical Society A, 137, 227-30.

Johnson, J. E. V. and Bruce, A.C. (1993) 'Gluck's Second Law: An Empirical Investigation of Horserace betting in Early and Late Races', Psychological Reports, 72, 1251-1268.

Kopelman, R.E. and Minkin, B.L. (1991) 'Towards a Psychology of Parimutuel Behaviour: test of Gluck's Laws', Psychological Reports, 68, 701-2.

Luce, R.,D. and Suppes, P. (1965) 'Preference Utility, and Subjective Probability', in Luce R.D. et al (eds.) Handbook of Mathematical Psychology, New York: John Wiley.

Sobel, Russell S. and S. Travis Raines (2003) 'An examination of the empirical derivatives of the favourite-longshot bias in racetrack betting' Applied Economics, 35, 371-385.

Snyder, W.W. (1978) 'Horse Racing: Testing the Efficient Markets Model', Journal of Finance, 33 (4), 1109-1118.

Thaler, R. and Ziemba, W. (1988) 'Parimutuel Betting Markets: Racetracks and Lotteries, Journal of Economic Perspectives, 2, 161-174.

Vaughan Williams, L. and Paton, D (1997). Why is there a Favourite-Longshot Bias in British Racetrack Betting Markets? Economic Journal, 107, 150-158.

Vaughan Williams, L (ed.) (2005) 'Information Efficiency in Financial and Betting Markets' Cambridge UK: Cambridge University Press. 
Wald, A. (1943) Tests of Statistical Hypotheses Concerning Several Parameters, when the Number of Observations is Large. Transactions of the American Mathematical Society, 54, 426482.

Watson, P.L. and Westin, R.B. (1975) 'Transferability of Disaggregate Mode Choice Models' Regional Science and Urban Economics, 5 (1), 227-249.

Winter, Stefan and Martin Kukuk (2008) 'Do horses like vodka and sponging? - On market manipulation and the favouritelongshot bias' Applied Economics, 40, 75-87. 